\title{
Pronounced $\alpha$-Synuclein Pathology in a Seeding- Based Mouse Model Is Not Sufficient to Induce Mitochondrial Respiration Deficits in the Striatum and Amygdala
}

\author{
Johannes Burtscher, ${ }^{1}$ Jean-Christophe Copin, ${ }^{1}{ }^{\circ}$ Carmen Sandi, $^{2}$ and ${ }^{\circ}$ Hilal A. Lashuel ${ }^{1}$
}

https://doi.org/10.1523/ENEURO.0110-20.2020

${ }^{1}$ Laboratory of Molecular and Chemical Biology of Neurodegeneration, Brain Mind Institute, École Polytechnique Fédérale de Lausanne, Lausanne, $\mathrm{CH}-1015$, Switzerland and ${ }^{2}$ Laboratory of Behavioral Genetics, Brain Mind Institute, EPFL, Lausanne, $\mathrm{CH}-1015$, Switzerland

\begin{abstract}
Increasing evidence suggests that cross talk between $\alpha$-synuclein pathology formation and mitochondrial dysfunction plays a central role in the pathogenesis of Parkinson's disease (PD) and related synucleinopathies. While mitochondrial dysfunction is a well-studied phenomenon in the substantia nigra, which is selectively vulnerable in PD and some models thereof, less information is available in other brain regions that are also affected by synuclein pathology. Therefore, we sought to test the hypothesis that early $\alpha$-synuclein pathology causes mitochondrial dysfunction and that this effect might be exacerbated in conditions of increased vulnerability in affected brain regions, such as the amygdala. We combined a model of intracerebral $\alpha$-synuclein pathology seeding with chronic glucocorticoid treatment, which models non-motor symptoms of PD and affects amygdala physiology. We measured mitochondrial respiration, reactive oxygen species (ROS) generation and protein abundance as well as $\alpha$-synuclein pathology in male mice. Chronic corticosterone administration induced mitochondrial hyperactivity in the amygdala. Although injection of $\alpha$-synuclein preformed fibrils (PFFs) into the striatum resulted in pronounced $\alpha$-synuclein pathology in both striatum and amygdala, mitochondrial respiration in these brain regions was not compromised, regardless of corticosterone treatment. Our results suggest that early stage $\alpha$-synuclein pathology does not influence mitochondrial respiration in the striatum and amygdala, even in corticosterone-induced respirational hyperactivity. We discuss our findings in light of relevant literature, warn of a potential publication bias and encourage scientists to report their negative results within the framework of this model.
\end{abstract}

Key words: amygdala; mitochondria; neurodegeneration; Parkinson's disease; synuclein

\section{Significance Statement}

We report that early stage $\alpha$-synuclein pathology by itself or in combination with exogenous corticosteroneinduced amygdala hyperactivity did not compromise mitochondrial respiration in the striatum and amygdala in one of the most commonly used models of synucleinopathies. These results may explain why, in the hands of many research groups, this model does not elicit pronounced Parkinson's disease (PD)-like symptoms in the absence of mitochondrial dysfunction. This despite the presence of significant $\alpha$-synuclein pathology in brain regions involved in non-motor (amygdala) and motor (striatum) disease symptoms. Our findings call for rigorous investigation of the short- and long-term effects of $\alpha$-synuclein pathology on mitochondrial function/dysfunction in this model, particularly in brain regions strongly affected by neurodegeneration such as the substantia nigra pars compacta. 


\section{Introduction}

The misfolding, aggregation and accumulation of $\alpha$-synuclein in Lewy bodies and the selective neurodegeneration of dopaminergic neurons are defining hallmarks of Parkinson's disease (PD), the most common neurodegenerative motor disease (Spillantini et al., 1997; Lashuel et al., 2013). Mutations or multiplications of the $\alpha$-synuclein encoding gene, SNCA, cause familial forms of PD (Polymeropoulos et al., 1997; Krüger et al., 1998; Singleton et al., 2003; Ibáñez et al., 2004; Zarranz et al., 2004), thereby suggesting a causal role of $\alpha$-synuclein in PD. Several lines of evidence support the Braak hypothesis of $\alpha$-synuclein pathology propagation during the progression of PD (Braak et al., 2003a,b), including evidence for (1) pathologic $\alpha$-synuclein spreading from host PD patient brains to mesencephalic transplants grafted into these brains (Kordower et al., 2008; Li et al., 2008); (2) intercellular transmission of $\alpha$-synuclein aggregates (Desplats et al., 2009; VolpicelliDaley et al., 2011); and (3) induction of $\alpha$-synuclein pathology formation and spreading in mouse brain by inoculation with recombinant $\alpha$-synuclein preformed fibrils (PFFs) or brain-derived aggregates from PD or multiple system atrophy (MSA) patients (Luk et al., 2012; Masuda-Suzukake et al., 2013; Recasens et al., 2014).

Mitochondrial dysfunctions, in particular deficiencies of the electron transport system, have been implicated in PD pathogenesis (Langston et al., 1983; Schapira et al., 1989) and is thought to play important roles in both neurodegeneration and $\alpha$-synuclein pathology formation (Hsu et al., 2000). Aggregated forms of $\alpha$-synuclein have also been shown to interfere with the regulation of mitochondrial import (Di Maio et al., 2016), mitochondrial membrane potential, reactive oxygen species (ROS) generation and mitochondrial morphology (Tapias et al., 2017; Grassi et al., 2018) and oxidative phosphorylation (Devi et al., 2008; Ludtmann et al., 2016, 2018; Mahul-Mellier et al., 2020). However, whether $\alpha$-synuclein pathology in the brain is sufficient to cause mitochondrial respiration dysfunction is not known. Animal models based on $\alpha$-synuclein pathology seeding provide unique opportunities to address this question.

Seeding and induction of $\alpha$-synuclein pathology in rodents by inoculation of the striatum (Luk et al., 2012) or the olfactory bulb (Rey et al., 2016) with PFFs results in

Received March 19, 2020; accepted May 19, 2020; First published June 2, 2020.

The authors declare no competing financial interests.

Author contributions: J.B., J.-C.C., C.S., and H.A.L. designed research; J.B. and J.-C.C. performed research; J.B. and J.-C.C. analyzed data; J.B. and H.A. L. wrote the paper.

This work was funded by École Polytechnique Fédérale de Lausanne and Union Chimique Belge, Société Anonyme.

Acknowledgements: We thank Olivia Zanoletti for excellent technical support and Somanath Jagannath and Salvatore Novello for constructive feedback.

Correspondence should be addressed to Hilal A. Lashuel at hilal. lashuel@epfl.ch.

https://doi.org/10.1523/ENEURO.0110-20.2020

Copyright (C) 2020 Burtscher et al.

This is an open-access article distributed under the terms of the Creative Commons Attribution 4.0 International license, which permits unrestricted use, distribution and reproduction in any medium provided that the original work is properly attributed. robust early $\alpha$-synuclein pathology (as assessed by staining for $\alpha$-synuclein phosphorylated at serine 129, pS129) in the amygdala (Burtscher et al., 2019) preceding motor symptoms. We reported a peak of pS129 $\alpha$-synuclein in limbic and cortical circuits around one to three months after injection that subsequently decreased over time. Such transiently high levels of pS129 $\alpha$-synuclein especially in the amygdala (Burtscher et al., 2019), although potentially mouse-strain dependent, are increasingly acknowledged by some groups (Rey et al., 2019) but not yet by others (Henderson et al., 2019).

As the human amygdala can also be profoundly affected in synucleinopathy (Nelson et al., 2018; Sorrentino et al., 2019), we initially thought such pathology could be related to prodromal and non-motor symptoms in PD. However, we recently reported surprisingly small behavioral effects associated with high levels of pathologic $\alpha$-synuclein in the mouse amygdala (Burtscher et al., 2019), suggesting that $\alpha$-synuclein pathology in the amygdala was not sufficient to cause major non-motor symptoms. Whether this is due to the high resistance of cells in the amygdala to the cellular stress conferred by pathologic $\alpha$-synuclein aggregates, or whether creeping cellular dysfunction at this stage precedes behavioral phenotypes is unknown. We hypothesized here that early $\alpha$-synuclein pathology perturbs mitochondrial function and thus causes detectable cellular dysfunction that precedes behavioral manifestation.

To investigate this hypothesis, we injected $\alpha$-synuclein PFFs into the striatum of adult male mice. Based on our previous results (Burtscher et al., 2019), we selected to study mitochondrial function at a time point where $\alpha$-synuclein pathology peaks in the amygdala, which was five to six weeks after injection (Burtscher et al., 2019). We characterized pathology using biochemistry and imaging approaches at this time point and studied mitochondrial functions using highresolution respirometry and concurrent assessment of mitochondrial ROS generation. All these assessments were performed for the amygdala and the site of injection, the striatum. To exclude the potential of the results being confounded by cellular loss-induced mitochondrial dysfunction, we did not investigate time points or brain regions characterized by apparent neuronal cell death.

In addition, we applied chronic corticosterone (in the drinking water) to a subset of mice to induce metabolic dysfunction in the amygdala, starting one month before PFF injection and until the animals were killed. Metabolic alterations in the amygdala have been reported on chronic glucocorticoid administration (Thobois et al., 2017). This approach allowed us to assess the influence of preexisting metabolic dysfunction in combination with $\alpha$-synuclein pathology on mitochondrial function.

\section{Materials and Methods}

\section{PFFs}

$\alpha$-Synuclein fibrils were prepared and characterized as described previously (Burtscher et al., 2019; Kumar et al., 2020). Briefly, a $325 \mu \mathrm{m}$ solution of pure recombinant mouse $\alpha$-synuclein protein (in PBS, pH 7.2) was centrifuged in $0.2 \mu \mathrm{m}$ filter tubes ( $5 \mathrm{~min}, 5000 \mathrm{rpm}$ ). To produce 
fibrils (PFFs), the supernatant was incubated under aggregation conditions $\left(4 \mathrm{~d}, 37^{\circ} \mathrm{C}\right)$ and shaking (at $\left.900 \mathrm{rpm}\right)$, as described previously (Burtscher et al., 2019). The resulting PFFs were sonicated (one 1-s pulse per $2 \mathrm{~s}$ for $10 \mathrm{~s}$ at $40 \%$ amplitude) and stored at $-80^{\circ} \mathrm{C}$ until use.

For characterization of the PFFs, samples were treated with $10 \mu \mathrm{M}$ thioflavin T (ThT; in $50 \mathrm{~mm}$ glycine, $\mathrm{pH}$ 8.5) in black 384-well plates (Nunc) and the extent of fibril formation was measured at $485 \mathrm{~nm}$ (excitation at $450 \mathrm{~nm}$ ) using a Bucher Analyst AD plate reader.

To assess the amount of fibrils formed and the monomers released, we used sedimentation $(100,000 \times g, 30 \mathrm{~min})$ and filtration assays $(14,000 \times g$ for $15 \mathrm{~min}$ through a $100-\mathrm{kDa}$ filter). Electron microscopy was applied for morphologic characterizations, as described previously (Burtscher et al., 2019; Kumar et al., 2020).

\section{Animals}

Male C57BL/6JRj mice (two to three months of age, three animals per cage) used for the in vivo experiments were housed at $23^{\circ} \mathrm{C}, 40 \%$ humidity, light from 7 A.M. to 7P.M. and dark from 7 P.M. to 7 A.M. with free access to standard laboratory rodent chow and water for in vivo experiments. Primary hippocampal cultures were derived from postnatal day (P) P0-2 pups of C57BL/6JRccHsd mice.

All animal experimentation procedures were approved by the Cantonal Veterinary Authorities (Vaud, Switzerland) and were performed in compliance with the European Communities Council Directive of 24 November 1986 (86/ $609 E E C)$. Every effort was taken to minimize the number of the animals and their stress.

For stereotactic surgeries, $5 \mu \mathrm{g}$ of PFFs in $2 \mu \mathrm{l}$ PBS was injected into the right dorsal striatum $(\mathrm{AP}+0.4, \mathrm{ML}+2$, DV -2.6) of fully anesthetized animals $(100 \mathrm{mg} / \mathrm{kg}$ ketamine and $10 \mathrm{mg} / \mathrm{kg}$ xylazine, i.p.) on stereotactic frames (Kopf Instruments) through a 34-gauge cannula using a 10- $\mu$ l Hamilton syringe (flow rate of $0.1 \mu \mathrm{l} / \mathrm{min}$ ).

Mice were given an overdose of pentobarbital $(150 \mathrm{mg} /$ $\mathrm{kg}$ ) for transcardial perfusion with heparinized saline, which was followed by $4 \%$ paraformaldehyde perfusion to prepare the tissue for histology ( $N=3$ per group, total $N=24)$. Mice for mitochondrial respiration studies $(N=9$ per group, $N=36$ ) were killed by neck dislocation, and exsanguination and tissues were directly dissected and prepared for high-resolution respirometry.

\section{Primary neuronal cultures, PFF treatment, and immunocytochemistry}

Primary hippocampal neurons were prepared from P02 C57BL/6JRccHsd mouse pups (Harlan) and were imaged as described before (Mahul-Mellier et al., 2020). Briefly, hippocampi were dissected in HBSS and digested by papain $\left(20 \mathrm{U} / \mathrm{ml}\right.$, Sigma-Aldrich) for $30 \mathrm{~min}$ at $37^{3} \mathrm{C}$. Papain activity was inhibited using a trypsin inhibitor (SigmaAldrich), and tissues were dissociated by trituration. The cells were resuspended in adhesion media (MEM, 10\% horse serum, 30\% glucose, L-glutamine, and penicillin/streptomycin; Life Technologies), and they were plated at a density of 250,000 cells $/ \mathrm{ml}$ in six-well plates coated with $0.1 \%(\mathrm{w} / \mathrm{v})$
poly-L-lysine in water (Brunschwig). Adhesion media were replaced by neurobasal medium (Life Technologies) containing B27 supplement (Life Technologies), L-glutamine, and penicillin/streptomycin (100 U/ml, Life Technologies) after 3 h. After $5 \mathrm{~d}$ in vitro, primary cultures were treated with $70 \mathrm{~nm}$ (corresponding to $\sim 1 \mathrm{ng} / \mu \mathrm{l}$ ) PFFs; $14 \mathrm{~d}$ later, the cells were washed in PBS, fixed in 4\% PFA for $20 \mathrm{~min}$, and immunostained. For Mito Tracker experiments, the cells were exposed to $100 \mathrm{~nm}$ MitoTracker Red CMXRos (Invitrogen) 30 min before fixation. For immunostaining, fixed cells were blocked with $3 \%$ BSA with $0.1 \%$ Triton X-100 in PBS for $30 \mathrm{~min}$, and then they were exposed to primary antibodies for $2 \mathrm{~h}$, washed, and incubated with secondary antibodies (plus DAPI) for $1 \mathrm{~h}$, washed and mounted using Fluoromount (Southern Biotech).

\section{Assessment of body composition}

Percentages of fat and lean masses of total body mass were measured by echo MRI before corticosterone/vehicle treatment (to ensure similar body composition across experimental groups) and eight weeks after treatment.

\section{Continuous exogenous corticosterone treatment}

Corticosterone (Sigma) was dissolved in $0.45 \%$ hydroxypropyl-b-cyclodextrin (Sigma) and administered (35 mg/l) to animals in drinking water continuously starting four weeks before surgery and continuing until the killing of the animals as described previously (Bacq et al., 2012). Control animals were administered the solvent vehicle $(0.45 \%$ hydroxyprop$\mathrm{yl-b}$-cyclodextrin) in the same manner.

\section{Histology and immunohistochemistry}

Perfused brains were postfixed in $4 \%$ paraformaldehyde, embedded in paraffin, and cut coronally to generate $4-\mu \mathrm{m}$ sections. Brain slices were dewaxed and epitope retrieval was performed for $20 \mathrm{~min}$ at $95^{\circ} \mathrm{C}$ in trisodium citrate buffer (10 mm, pH 6.0) in a retriever (Labvision) was applied. For immunofluorescence, sections were blocked for 60 min in 3\% bovine serum albumin in PBS containing $0.1 \%$ Triton $\mathrm{X}-100$. Primary antibodies were applied overnight at $4^{\circ} \mathrm{C}$, followed by secondary antibodies (plus DAPI) for $60 \mathrm{~min}$ at room temperature (RT) before mounting the slides using Fluoromount (Southern Biotech). Sections of $N=3$ animals from each time point [30 d postinjection (dpi) and $360 \mathrm{dpi}$ of only PFFs or PBS, total $N=12$ ] were used for pS129 staining together with ubiquitin, p62 or thioflavin S (ThS). For ThS staining, sections were incubated for $15 \mathrm{~min}$ in $0.01 \%$ ThS and washed in $80 \%$ ethanol, followed by washing in water and then PBS before blocking and immunostaining.

Sections of $N=3$ animals per group (total $N=12$ ) at 60 dpi (corticosterone/vehicle and PFF/PBS) were used for staining for pS129, N-terminal (1-20) $\alpha$-synuclein and TOM20, with or without proteinase $\mathrm{K}$ treatment $(8 \mathrm{~min}$ in $1 \mu \mathrm{g} / \mathrm{ml}$ of proteinase $\mathrm{K}$ in $50 \mathrm{~mm}$ Tris- $\mathrm{HCl}$ buffer at $\mathrm{pH} 7.4$ before staining). Imaging was performed with a Zeiss LSM700 confocal microscope.

Other sections of the same animals were used for 3,3'diaminobenzidine (DAB)-staining and exposed to $3 \%$ 
$\mathrm{H}_{2} \mathrm{O}_{2}$ in PBS for 30 min before blocking for 60 min in $3 \%$ bovine serum albumin in PBS containing $0.1 \%$ Triton X100 at RT. A primary antibody against $\alpha$-synuclein pS129 (Wako Chemicals USA, 014-20281, 1:10,000) was incubated with the sections overnight at $4^{\circ} \mathrm{C}$, and ImmPRESS reagent anti-mouse $\lg \mathrm{G}$ was applied for $40 \mathrm{~min}$ at $\mathrm{RT}$ followed by incubation for $10 \mathrm{~min}$ in DAB dissolved in $50 \mathrm{~mm}$ Tris buffer and $0.06 \% \mathrm{H}_{2} \mathrm{O}_{2}$. Sections were counterstained with Mayer's hematoxylin, mounted with Fluoromount (Southern Biotech), and imaged using an Olympus AX70 microscope.

\section{Respirometry}

After killing, striatum and amygdala-enriched tissues (both from the hemisphere of injection and contralateral hemisphere) were dissected on ice using a mouse brain matrix (Agnthos). Wet tissue was weighed and collected in icecold BIOPS [2.8 mM $\mathrm{Ca}_{2} \mathrm{~K}_{2}$ EGTA, 7.2 mM $\mathrm{K}_{2}$ EGTA, $5.8 \mathrm{~mm}$ ATP, $6.6 \mathrm{mM} \mathrm{MgCl}_{2}, 20 \mathrm{~mm}$ taurine, $15 \mathrm{~mm}$ sodium phosphocreatine, $20 \mathrm{~mm}$ imidazole, $0.5 \mathrm{~mm}$ dithiothreitol, and $50 \mathrm{~mm}$ MES; pH 7.1]. Then, the tissue was homogenized in ice-cold MiR05 [0.5 mм EGTA, 3 mм $\mathrm{MgCl}_{2}$, $60 \mathrm{~mm}$ potassium lactobionate, $20 \mathrm{~mm}$ taurine, $10 \mathrm{~mm} \mathrm{KH}_{2} \mathrm{PO}_{4}, 20 \mathrm{~mm}$ HEPES, 110 $\mathrm{mm}$ sucrose, and $0.1 \%(\mathrm{w} / \mathrm{v}) \mathrm{BSA} ; \mathrm{pH} 7.1$ ] using a pestle for Eppendorf tubes at a concentration of $1 \mathrm{mg}$ of tissue (wetweight) per $10 \mu \mathrm{l}$ of MiR05. Respiration was measured in parallel to mitochondrial ROS production $\left(\mathrm{O}_{2}{ }^{-}\right.$and $\left.\mathrm{H}_{2} \mathrm{O}_{2}\right)$ at $37^{\circ} \mathrm{C}$ in the Oroboros $\mathrm{O} 2 \mathrm{k}$ equipped with the O2K FluoLED2 Module (Oroboros Instruments). For mitochondrial ROS measurement, LEDs for green excitation were applied and a concentration of $1 \mathrm{mg}$ of wet tissue per milliliter of MiR05 was added to final concentrations of $10 \mu \mathrm{M}$ amplex red, $1 \mathrm{U} / \mathrm{ml}$ horseradish peroxidase, and $5 \mathrm{U} / \mathrm{ml}$ superoxide dismutase in $2 \mathrm{ml}$ of MiR05 per O2K chamber. Calibration was performed by $5-\mu$ l titrations of $40 \mu \mathrm{M} \mathrm{H}_{2} \mathrm{O}_{2}$.

Respirational states were assessed using a standard high-resolution respirometry protocol: nicotinamide adenine dinucleotide (NADH)-pathway respiration in the LEAK $\left(\mathrm{N}_{L}\right)$ state was initiated using malate $(2 \mathrm{mM})$, pyruvate $(10$ $\mathrm{mm})$, and glutamate $(20 \mathrm{~mm})$. Oxidative phosphorylation $\left(\mathrm{N}_{P}\right)$ was stimulated by ADP $(5 \mathrm{~mm})$. Succinate $(10 \mathrm{~mm})$ addition yielded $\mathrm{NADH}$ - and succinate-linked respiration in oxidative phosphorylation $\left(\mathrm{NS}_{P}\right)$ and in the uncoupled state $\left(\mathrm{NS}_{E}\right)$ after titration $(\Delta 0.5 \mu \mathrm{M})$ of carbonyl cyanide m-chlorophenyl hydrazine (CCCP). Complex I inhibition by rotenone $(0.5 \mu \mathrm{M})$ allowed analysis of succinate-linked respiration in the uncoupled state (SE). All oxygen fluxes were corrected for residual (nonoxidative phosphorylation associated) oxygen consumption, ROX, after antimycin A was added. Respiratory acceptor control ratios (RCRs) were calculated as $\mathrm{N}_{L} / \mathrm{NS}_{P}$. Flux control ratios (FCRs) were assessed for $\mathrm{NADH}-\left(\mathrm{N}_{P} / \mathrm{NS}_{E}\right)$ succinate-driven respiration $\left(S E / \mathrm{NS}_{E}\right)$. Mitochondrial ROS values are presented as mitochondrially generated $\mathrm{O}_{2}{ }^{-}$and $\mathrm{H}_{2} \mathrm{O}_{2}$ per mg of wet weight and second, ROS values are corrected for background.

\section{Western blotting and fractionated sample preparations}

After using the required volume for respirometry, phosphatase inhibitor mixes (Sigma, P5726 and P0044) and protease inhibitor mix (Sigma, P8340) were added to tissue homogenates at a ratio of 1:100, and then $1 \mathrm{mM}$ phenylmethylsulfonyl fluoride (PMSF) was added. Then, the samples were snap-frozen in liquid nitrogen and stored at $-80^{\circ} \mathrm{C}$. For extraction of Triton X-100 soluble and insoluble fractions, homogenates were diluted 1:1 in 1\% Triton X-100/Tris-buffered saline (TBS; $50 \mathrm{~mm}$ Tris and $150 \mathrm{~mm}$ $\mathrm{NaCl}, \mathrm{pH}$ 7.5) that included protease and phosphatase inhibitor mixes and PMSF at the same concentration as indicated above (total fractions). Homogenates were sonicated 10 times at a $0.5-\mathrm{s}$ pulse $(20 \%$ amplitude, Sonic Vibra Cell, Blanc Labo), and then they were incubated on ice for $30 \mathrm{~min}$ and centrifuged at 100,000 $\times \mathrm{g}\left(30 \mathrm{~min}, 4^{\circ}\right.$ C). The supernatant was used as a soluble fraction, and the pellet was washed in $1 \%$ Triton X-100/TBS, sonicated as above, and centrifuged again at 100,000 $\times g(30 \mathrm{~min}$, $4^{\circ} \mathrm{C}$ ). The pellet (insoluble fraction) was resuspended in $2 \%$ sodium dodecyl sulfate (SDS)/TBS including protease and phosphatase inhibitor mixes and PMSF at the same concentration, as indicated above, and sonicated $15 \times$ at a 0.5 -s pulse (20\% amplitude). While sufficient tissue for tissue extractions was available for striatal samples ( $N=8-9$ per condition), two to three amygdala samples had to be pooled (at least $N=3$ per condition).

Protein concentrations of different fractions were assessed using a BCA assay. A total of $15-20 \mu \mathrm{g}$ of proteins was loaded on a $16 \%$ tricine gels and transferred onto a nitrocellulose membrane (Fisher Scientific) using a semidry system (Bio-Rad); 30 min of blocking in Odyssey blocking buffer (Li-Cor Biosciences) was followed by incubation overnight at $4^{\circ} \mathrm{C}$ with primary antibodies. Membranes were then washed in $0.01 \%(\mathrm{v} / \mathrm{v})$ Tween 20 (Sigma-Aldrich) in PBS (PBS-T), and secondary antibodies were applied for $1 \mathrm{~h}$ at RT. After final washing in PBS$\mathrm{T}$, membranes were scanned using a Li-COR scanner ( $\mathrm{Li}-$ Cor Biosciences).

\section{Antibodies}

The antibodies used in this study are listed in Table 1.

\section{Statistics}

Corticosterone versus vehicle and PFF injections versus PBS injections were compared in a $2 \times 2$ statistical design. Two-way ANOVAs were calculated, in cases for which Gaussian normality could be assumed. Normality was tested using the Anderson-Darling, D'Agostino-Pearson omnibus, Shapiro-Wilk, and Kolmogorov-Smirnov tests.

All absolute values and Western blotting values are presented as the mean $\pm \mathrm{SD}$. Normalized respirational and mitochondrial $R O S$ values are presented as the mean \pm SEM.

\section{Results}

\section{Mitochondrial coupling efficiency is maintained in the presence of both seeded $\alpha$-synuclein pathology and corticosterone induced alterations in body composition}

First, we verified the effects of chronic corticosterone and injection of $\alpha$-synuclein PFFs (Fig. 1A). Similar to our recent report (Burtscher et al., 2019), chronic 
Table 1: Antibodies

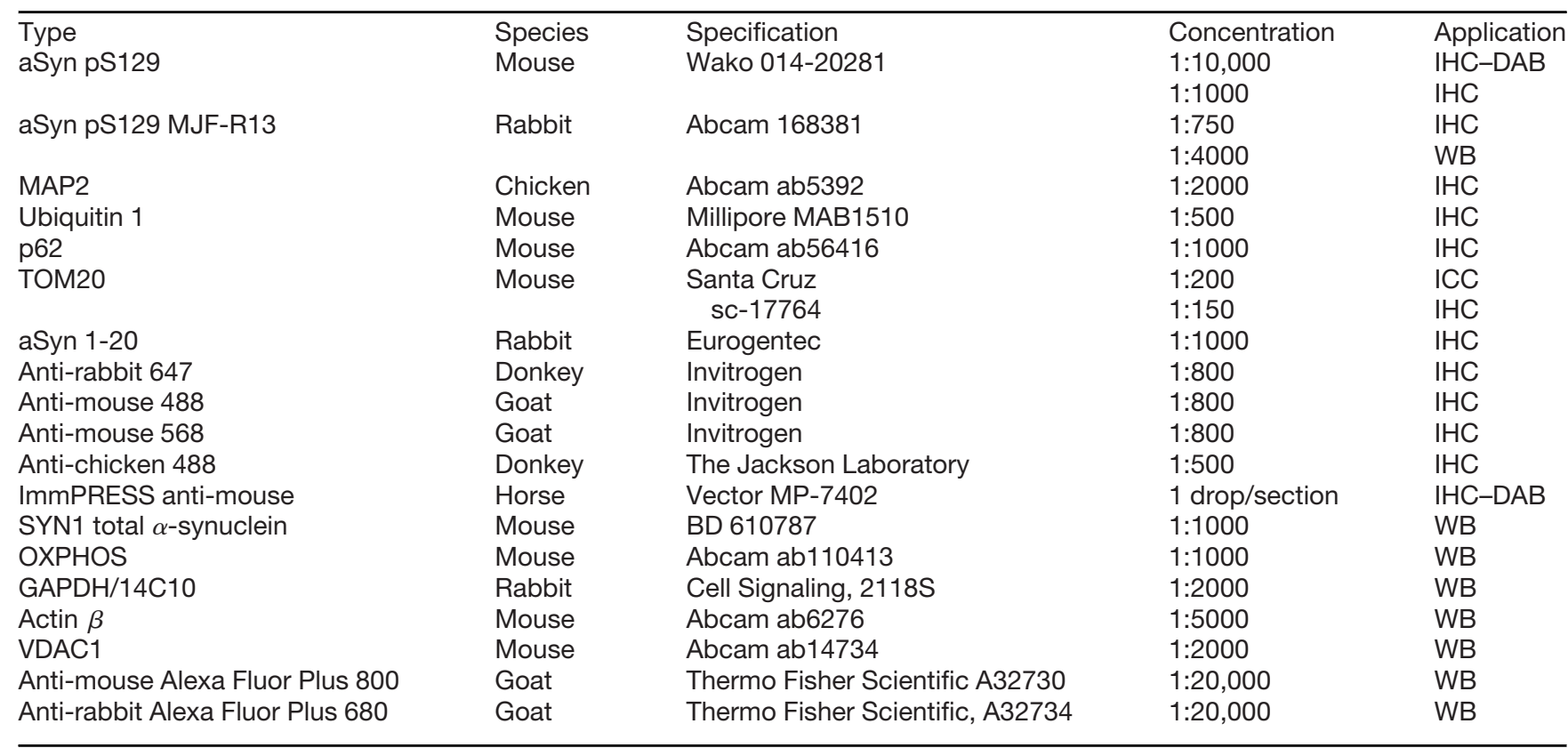

IHC, immunohistochemistry; ICC, immunocytochemistry; WB, Western blotting

corticosterone increased body fat tissue content, as assessed by Echo MRI ( $F_{\text {corticosterone(1,31) }}=69,45, p<0,0001$; Fig. $1 B$ ), independently of PFF injection. $\alpha$-Synuclein pS129 pathology was confirmed by histology in the ipsilateral striatum and amygdala (Fig. 1C). We observed similar pathology patterns in the PFF groups, regardless of corticosterone treatment, as reported previously (Burtscher et al., 2019).

Previous studies have shown that $\alpha$-synuclein is subjected to proteolytic processing during or after its aggregation, which leads to both $\mathrm{C}$ - and N-terminal truncation of the protein (Baba et al., 1998; Gai et al., 1999; Grassi et al., 2018; Mahul-Mellier et al., 2018). Therefore, Western blot analysis was performed to investigate $\alpha$-synuclein processing both in the striatum and amygdala five to six weeks after striatal PFF-injection. Several truncated forms of $\alpha$-synuclein (running at $\sim 12 \mathrm{kDa}$ ), a signature of pathologic $\alpha$-synuclein (Mahul-Mellier et al., 2018), were observed in ipsilateral (hemisphere of injection; Fig. 1D) total striatal fractions of all PFF conditions, although there was high variation in levels of these truncated forms of $\alpha$-synuclein. Virtually all of the $\alpha$-synuclein detected in all insoluble ipsilateral striatal fractions of PFF but not PBS conditions was truncated (Fig. 1E). Full-length $\alpha$-synuclein (15 kDa) levels were similar in total striatal fractions. In fractionated amygdala samples, no or very little truncated $\alpha$-synuclein was detected even in samples of PFFinjected mice. No $\alpha$-synuclein pS129 signal was detected in any fraction by Western blotting, possibly due to dilution of the tissue, where the pathology was localized.

Next, we assessed general mitochondrial parameters, mitochondrial protein levels, and coupling efficiency. VDAC1 levels, as well as mitochondrial coupling efficiencies, estimated by mitochondrial RCRs, were similar across groups both in the striatum (Fig. $1 F-H$ ) and amygdala (Fig, 1/-K).
Immunohistochemical analyses demonstrated an increasing immunoreactivity for the pS129-positive $\alpha$-synuclein with other $\alpha$-synuclein pathology markers (ubiquitin, ThS, and p62) over time in the striatum (Fig. $2 A$ ) and the amygdala (Fig. 2B).

To investigate potential colocalization of $\alpha$-synuclein pathology with functional mitochondria, we labeled primary hippocampal neurons, in which $\alpha$-synuclein pathology has been seeded $14 \mathrm{~d}$ before, with Mito Tracker. We indeed detected strong colocalization of pS129 with mitochondrial markers (Fig. 2C; Mahul-Mellier et al., 2020). Similar colocalization was also observed by co-immunostaining of brain sections for the outer mitochondrial membrane protein TOM20 and pS129 in neurons in the amygdala 60 dpi (Fig. 2D), which also contained proteinase K-resistant $\alpha$-synuclein aggregations (Fig. 2E).

\section{Corticosterone treatment, but not $\alpha$-synuclein pathology, alters mitochondrial respiration in the amygdala}

Having validated that the applied treatments induced the expected phenotypes, high-resolution respirometry was applied concomitantly with amplex red fluorometry to assess mitochondrial respiration and ROS production in the striatum and amygdala tissues. In the presence of $\mathrm{NADH}$-linked substrates and the absence of adenosine diphosphate (ADP, LEAK-state $\mathrm{N}_{L}$ ), respiration in the amygdala, was increased in corticosterone-treated mice (Fig. $3 A$ ), but not in the striatum (Fig. $3 B$ ). In the LEAKstate $\mathrm{N}_{L}$ mitochondrial Complex I, shuttling of electrons from NADH generates a proton gradient that is not used for oxidative phosphorylation due to the unavailability of ADP. Thus, these conditions constitute a dissipative state of oxygen consumption that is primarily associated with 
A

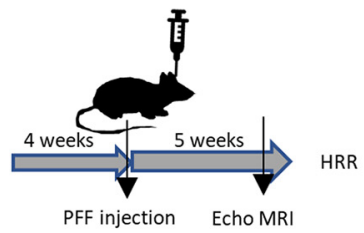

B

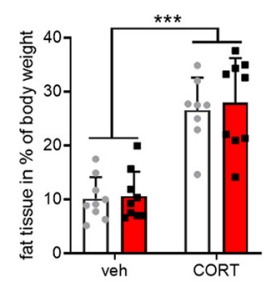

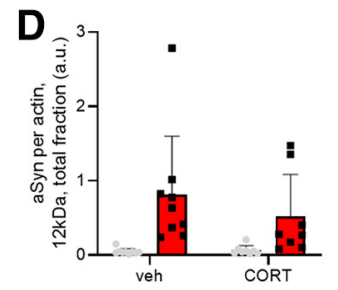

C
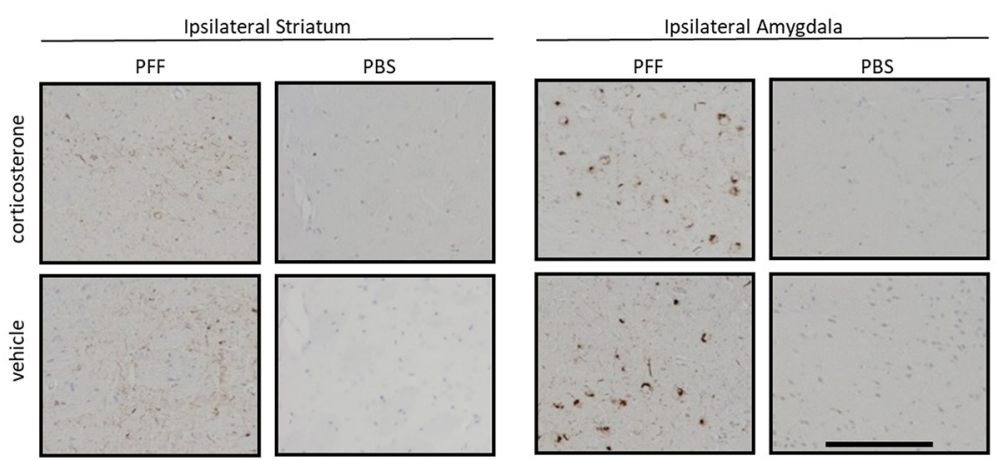

$\mathbf{F}$

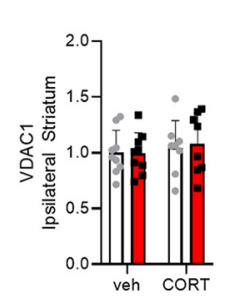

G

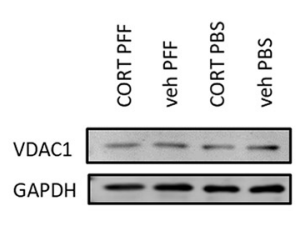

$\mathbf{H}$

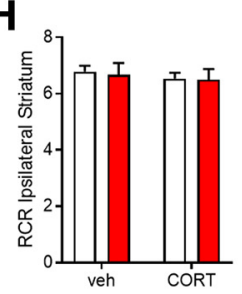

I

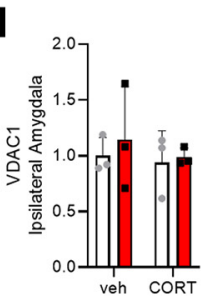

E
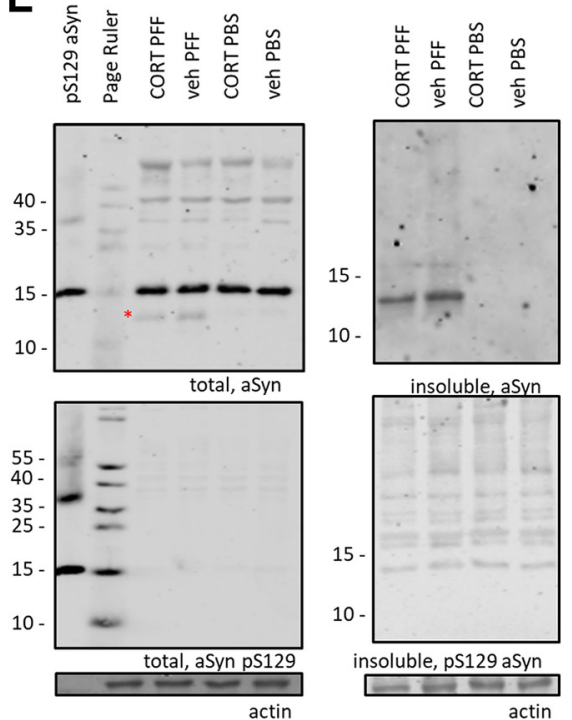

insoluble, aSyn

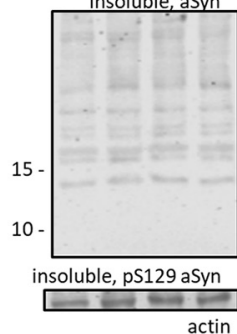

J
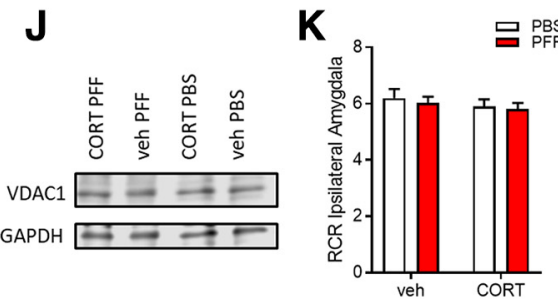

Figure 1. Effects of chronic corticosterone treatment and of $\alpha$-synuclein (aSyn) inoculation. Animals were treated with corticosterone (CORT) or a solvent vehicle (veh) in the drinking water for one month, after which they were injected unilaterally in the dorsal striatum with $5 \mu \mathrm{g}$ of PFFs or solvent (PBS). CORT/veh treatment was continued until approximately five weeks after surgery when the animals were killed $(\boldsymbol{A})$. Fat per body weight was increased after eight weeks of CORT treatment $(\boldsymbol{B})$. Six weeks after PFF injection $\alpha$-synuclein pathology ( $\alpha$-synuclein pS129 immunostaining) was observed both in the striatum (mainly neuritic) and in the amygdala (mainly somatic; $\mathbf{C}$ ). The striatum and amygdala were dissected for high-resolution respirometry, and residual tissues were used for biochemical analyses. The PFF-injected striatum contained truncated $\alpha$-synuclein (running at $12 \mathrm{kDa}$ ) in total homogenate, as quantified in $\boldsymbol{D}$ and represented in $\boldsymbol{E}$ (the asterisk indicates truncated $12 \mathrm{kDa} \alpha$-synuclein), which was even more abundant in insoluble fractions $(\boldsymbol{E})$. VDAC1 protein levels and mitochondrial RCRs were similar across groups both in the striatum $(\boldsymbol{F}-\boldsymbol{H})$ and in the amygdala $(\boldsymbol{I}-\boldsymbol{K})$; $* * * p<0.001$; two-way ANOVAs were performed. pS129 $\alpha$-synuclein label for Western blotting lanes denotes recombinant protein controls. Scale bar: $200 \mu \mathrm{m}(\boldsymbol{C})$.

heat production. Similarly, respiration was higher in the corticosterone condition in the $\mathrm{NADH}$-driven oxidative phosphorylation state in the amygdala (saturating concentrations of ADP, $\mathrm{N}_{P}$; Fig. $3 C$ ) but not in the striatum (Fig. $3 D$ ). $N_{P}$ is a respirational state also linked to Complex I and driven by NADH-linked substrates, but the availability of ADP enables oxidative phosphorylation. Oxidative phosphorylation-mediated respiration was then increased by the addition of succinate, a substrate for mitochondrial Complex II, yielding NADH- and succinate-driven oxidative phosphorylation $\left(\mathrm{NS}_{P}\right.$; Fig. $\left.3 E, F\right)$. The addition of a chemical uncoupling agent then allowed the induction of states in which respiration is uncoupled from oxidative phosphorylation. Similar to $\mathrm{NS}_{P}, \mathrm{NADH}$ - and succinatedriven uncoupled $\left(\mathrm{NS}_{E}\right.$; Fig. $\left.3 G, H\right)$ respiration was also higher in the amygdala (Fig. $3 E, G$ ), but not in the striatum (Fig. $3 F, H)$, in the corticosterone condition. Finally, in the succinate-driven, uncoupled state after Complex I inhibition (SE) using rotenone, no differences were observed in the amygdala (Fig. 3/) or in the striatum (Fig. 3J). Values for absolute respiration (per wet weight) and mitochondrial ROS production per brain region and normalizations to VDAC1 protein levels or total protein levels, as well as information on the statistical analyses are shown in Table 2.

To assess qualitative changes in respiration control, FCRs were calculated. While there were no differences in $\mathrm{NADH}$-driven $\left(\mathrm{N}_{P}\right)$ FCRs in the presence of ADP between corticosterone and vehicle control groups (Fig. 4A), FCR was reduced for the uncoupled, succinate-driven state $\left(N_{E}\right)$ in corticosterone conditions $\left(F_{\text {corticosterone }(1,30)}=6634\right.$, $p=0,015)$ in the ipsilateral striatum (Fig. 4B). In the amygdala, the NADH-driven $\left(\mathrm{N}_{P}\right)$ FCR was higher in corticosterone conditions $\left(F_{\text {corticosterone(1,29) }}=5907, p=0,021\right.$; Fig. $4 C)$, but there were no significant differences compared with vehicle control groups in noncoupled, succinatedriven $\left(\mathrm{N}_{E}\right)$ FCR (Fig. 4D).

We hypothesized that hyperactivity of the amygdala following chronic corticosterone treatment, or exposure to $\alpha$-synuclein pathology might result in increased mitochondrial ROS generation. However, amplex red fluometry 
A Striatum

pS129

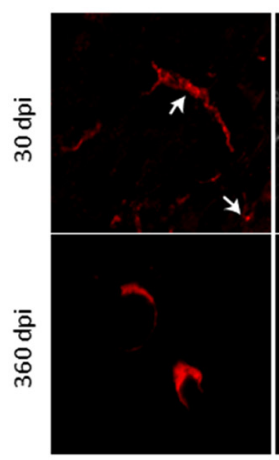

Ubiquitin

ThS

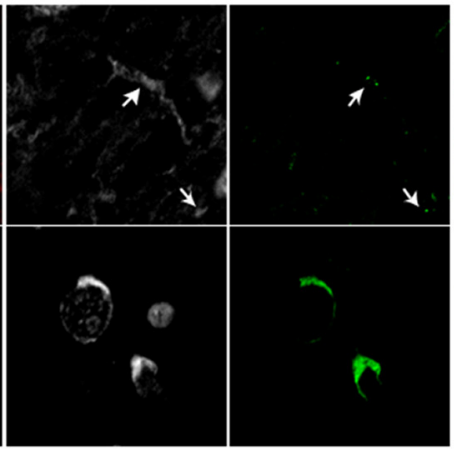

$30 \mathrm{dpi}$

B

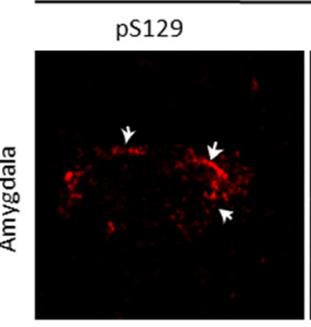

Ubiquitin

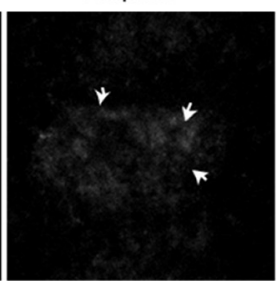

Merge + DAPI

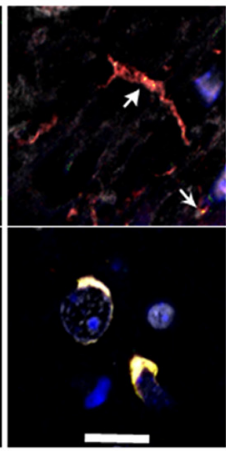

pS129

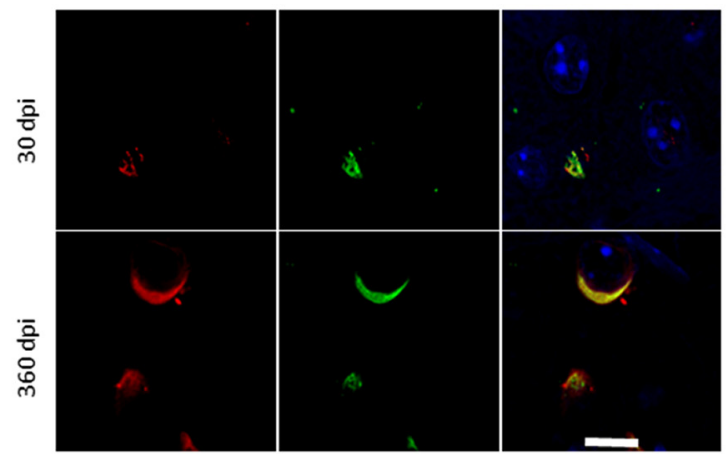

$180 \mathrm{dpi}$

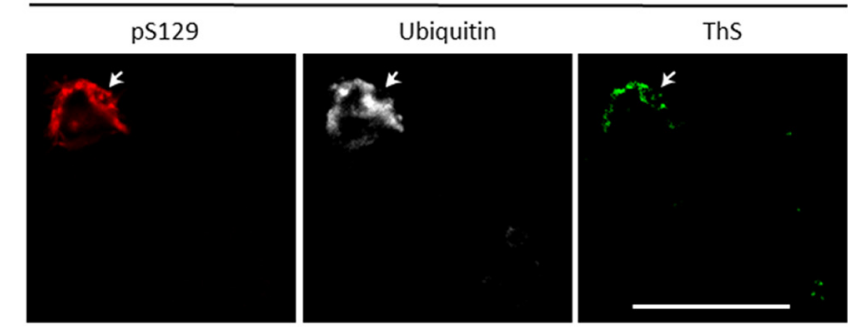

ThS

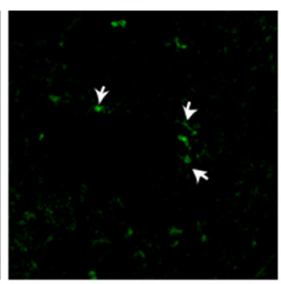

D

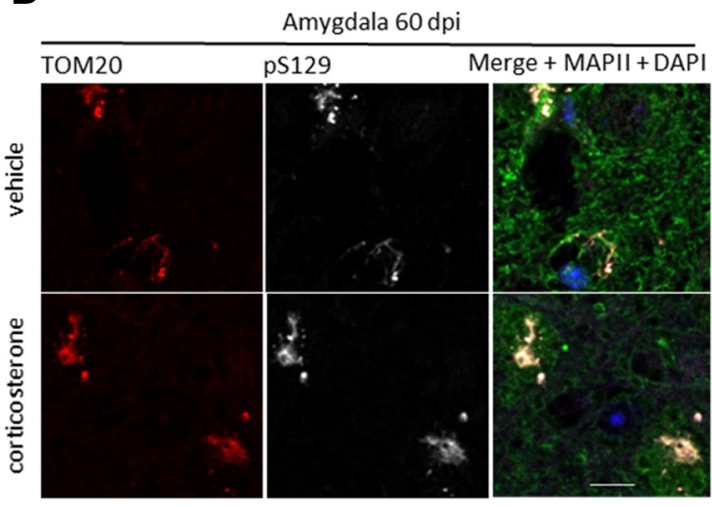

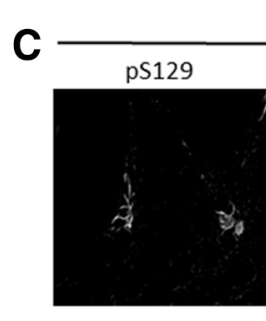

E

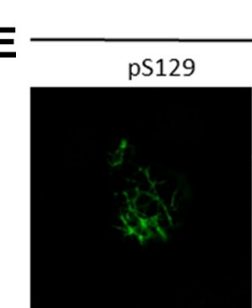

Primary hippocampal neurons mitotracker

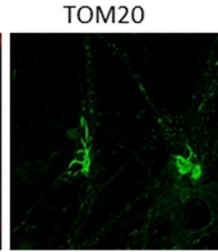

Amygdala 60 dpi, PK-treatment aSyn1-20
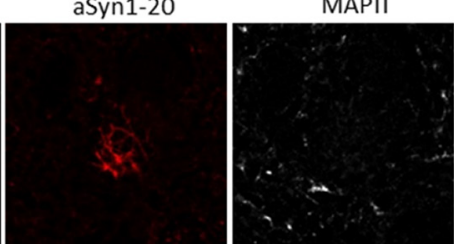

Merge + DAPI

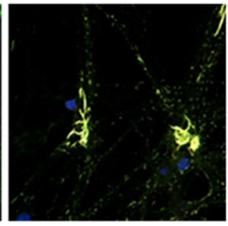

Merge + DAPI

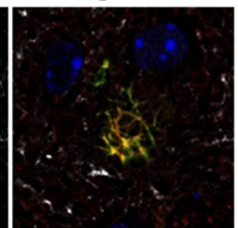

Figure 2. Characterization of $\alpha$-synuclein pathology formation. In the striatum, pS129 immunoreactivity at 30 dpi revealed that the protein colocalized in peripheral cell compartments with ubiquitin, and there was some overlap with ThS and p62. This colocalization was more pronounced and perinuclear at $360 \mathrm{dpi}(\boldsymbol{A})$. In the amygdala, similar colocalizations were observed at $30 \mathrm{dpi}$, and it was even more pronounced at $180 \mathrm{dpi}(\boldsymbol{B})$. In primary hippocampal neurons $14 \mathrm{~d}$ after treatment with $70 \mathrm{~nm}$ PFFs, pS129 colocalized strongly with the mitochondrial markers TOM20 and Mito Tracker $(\boldsymbol{C})$, with similar colocalizations being observed ex vivo at 60 dpi in the amygdala both in the chronic corticosterone and control condition $(\boldsymbol{D})$. The aggregates in the amygdala were resistant to proteinase $\mathrm{K}(\mathrm{PK})$ at this time point $(\boldsymbol{E})$. Green in the merged image in $\boldsymbol{D}$ corresponds to MAPII staining, and blue represents DAPI staining. Scale bars: $10 \mu \mathrm{m}(\boldsymbol{A}), 20 \mu \mathrm{m}(\boldsymbol{B})$, and $10 \mu \mathrm{m}(\boldsymbol{D}$, also for $\boldsymbol{C}, \boldsymbol{E})$. Arrows in $\boldsymbol{A}$ and $\boldsymbol{B}$ highlight examples of colocalizations.

revealed no differences in mitochondrial ROS production either in the striatum (Fig. 4E,F) or amygdala (Fig. 4G,H).

\section{Discussion}

Following up on our findings that $\alpha$-synuclein pathology in mouse amygdala did not cause strong behavioral deficits (Burtscher et al., 2019), we investigated here, whether $\alpha$-synuclein pathology, as defined above, was sufficient to cause mitochondrial dysfunction in the amygdala or at the site of injection (striatum). In the applied model, histologic staining of pS129 $\alpha$-synuclein showed a peak in levels between one and three months in the amygdala that decreased thereafter. Conversely, in the striatum, the pathology does not decrease but changes from predominantly neuritic localization at the investigated time point to successively more perinuclear localization at a later time 


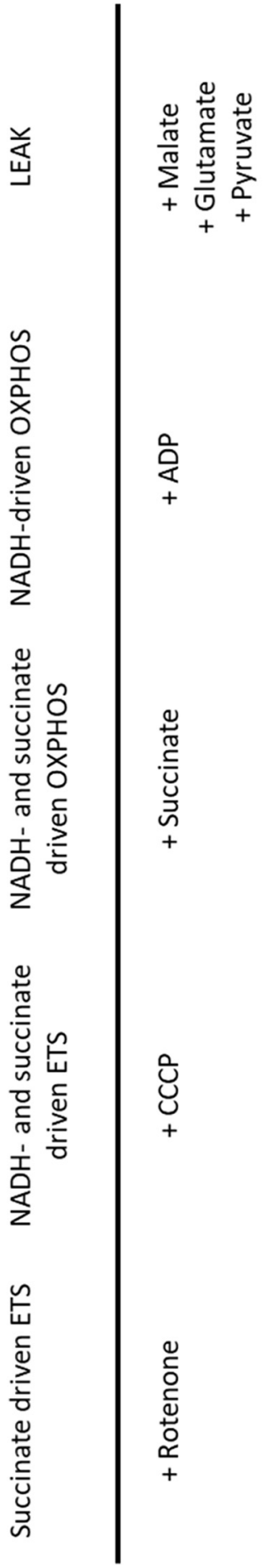

A

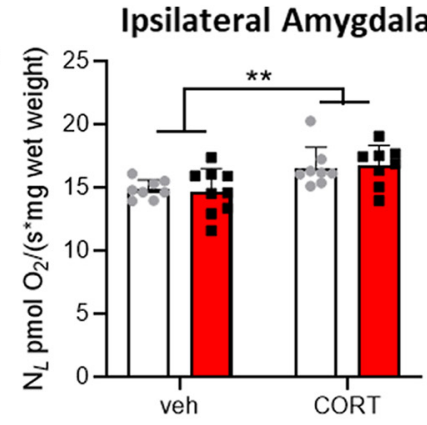

C

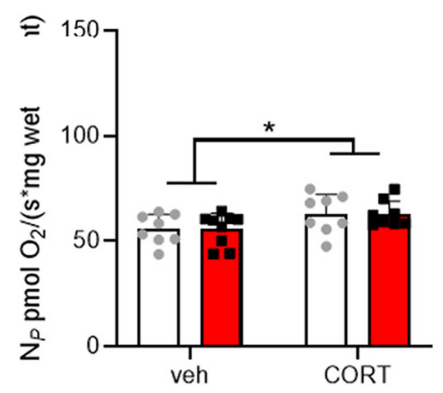

E

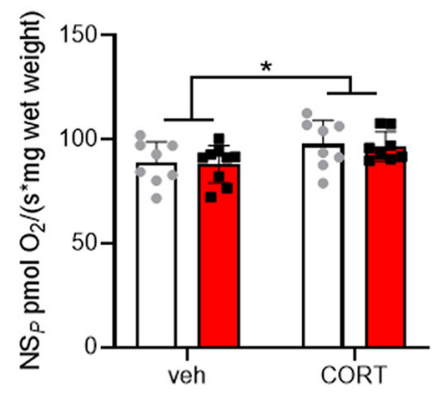

G
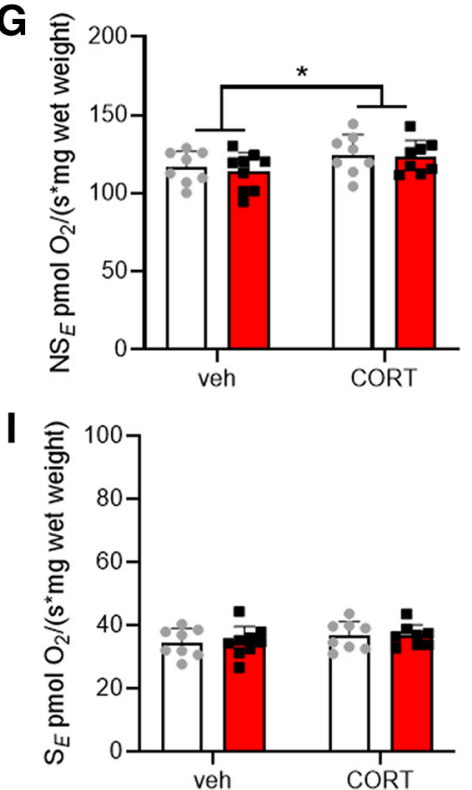

B

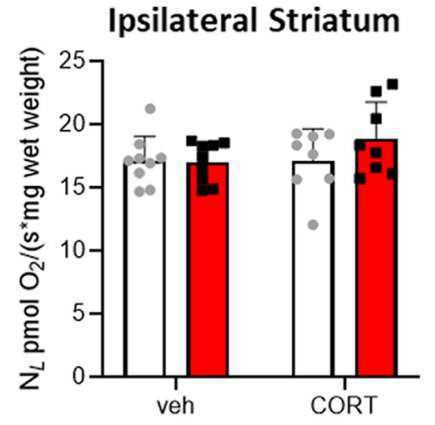

D

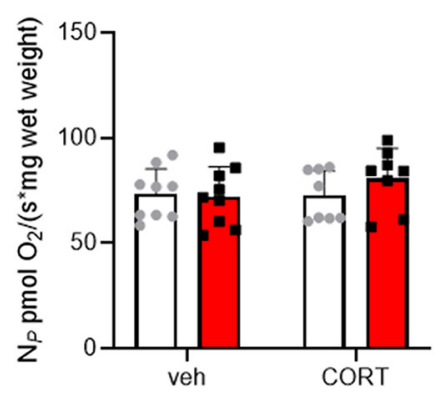

$\mathbf{F}$

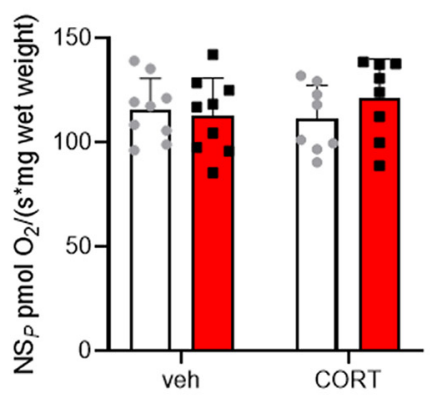

H
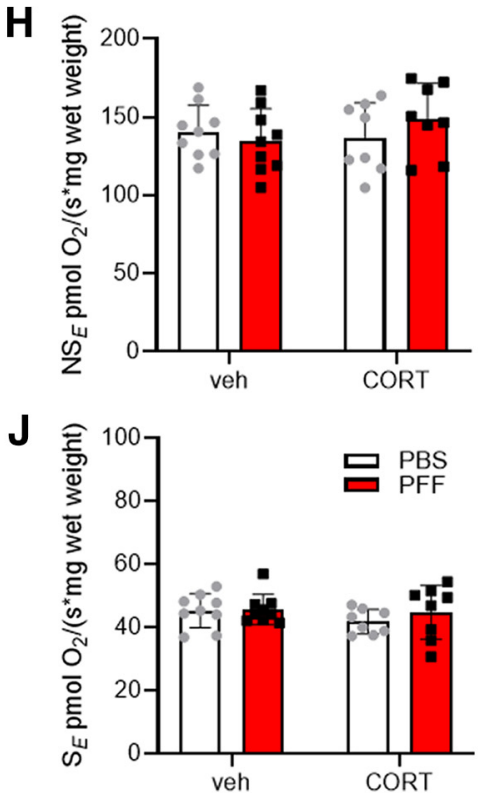

Figure 3. Testing mitochondrial functions ex vivo. The striatum and amygdala were dissected for high-resolution respirometry nine weeks after corticosterone (CORT) or vehicle (veh) treatment and/or after intrastriatal injection of $5 \mu \mathrm{g}$ PFFs or solvent (PBS). Data from the hemispheres of injections (=ipsilateral) are depicted. The LEAK state in the presence of NADH substrates $\left(N_{L}\right)$ was measured $(\boldsymbol{A}, \boldsymbol{B})$, followed by addition of ADP yielding NADH-driven oxidative phosphorylation $\left(\mathrm{N}_{\mathrm{P}}\right)$ in $(\boldsymbol{C}, \boldsymbol{D})$ succinate to drive oxidative phosphorylation via both Complex I and Complex II (NS $; \boldsymbol{E}, \boldsymbol{F}$ ) and CCCP to achieve the electron transport system maximum capacity (ETS, NS $\left.\mathrm{E}_{\mathrm{E}} \boldsymbol{G}, \boldsymbol{H}\right)$. Subsequent inhibition of Complex I by rotenone resulted in succinate-driven, uncoupled respiration (SE; $\boldsymbol{I}$, J). Respirational values of all states are given for the amygdala and striatum (hemisphere of injection = ipsilateral). The table to the 
continued

right indicates the respirational state and substance additions according to the SUIT (substrate, uncoupler, inhibitor titration) protocol. Two-way ANOVA was performed; see Table 2 for detailed results. The main effects for CORT are indicated; $* p<0.05$ and $* * p<0.01$.

points (Burtscher et al., 2019). In the present study, we were interested in the interplay between mitochondrial dysfunction and $\alpha$-synuclein pathology at the time point where pS129 $\alpha$-synuclein immunoreactivity peaks in the amygdala. Therefore, we cannot rule out progressive mitochondrial dysfunction at later time points in this model, e.g., in the striatum.

Impaired electron transport chain function due to the presence or accumulation of aggregated forms of $\alpha$-synuclein has been repeatedly reported in cellular models (Chinta et al., 2010; Reeve et al., 2015; Tapias et al., 2017; Kim et al., 2018; Wang et al., 2019), especially at late stages of aggregation formation (Mahul-Mellier et al., 2020). However, functional assessment of mitochondrial respiration in in vivo models of $\alpha$-synuclein seeding and pathology spreading remains lacking. Therefore, we aimed to study mitochondrial respiration directly on fresh brain tissue from regions affected by $\alpha$-synuclein pathology using ex vivo respirometry, which is the gold standard used to assess mitochondrial function.

We did not observe differences in absolute respiration related to $\alpha$-synuclein pathology both in the amygdala and the striatum. In contrast, chronic corticosterone treatment (associated with apparent depression-like phenotypes but not with significantly changed $\alpha$-synuclein pathology; Burtscher et al., 2019) increased mitochondrial respiration in the amygdala. The observed elevated respiration is in line with previous reports that systemic administration of corticosterone can increase the activity of the basolateral amygdala (Kavushansky and Richter-Levin, 2006). Furthermore, the respirometry protocols applied here allowed the identification of primarily NADH-linked substrates that drive this increased respiration.

To investigate potential qualitative changes in respiration patterns, we calculated FCRs (Gnaiger, 2009) and detected a reduced succinate-driven FCR in corticosterone conditions in the striatum. A higher succinate-driven FCR after the surgical intervention in the absence of exogenous corticosterone might be an adaptative response of the damaged tissue (Lukyanova and Kirova, 2015; Weilnau et al., 2018). Protein aggregation is believed to induce conditioning-like cellular adaptations (Mao and Crowder, 2010). Liu and colleagues reported less efficient preconditioningrelated adaptations if animals were treated with exogenous corticosterone (Liu and Zhou, 2012) and the HPA (hypothalamus-pituitary gland-adrenal gland) axis is intimately linked with molecular adaptation to stressors (Rybnikova and Samoilov, 2015), which might explain the absence of succinate-driven FCR upregulation in the corticosterone condition. The NADH-driven FCR in the oxidative phosphorylation state was higher in the corticosterone conditions in the amygdala, confirming the focal role of Complex $I$ in the observed effect of enhanced respiration after chronic corticosterone administration.

Misfolded $\alpha$-synuclein has previously been associated with oxidative stress (Hsu et al., 2000). Additionally, chronic corticosterone treatment has been demonstrated to result in a dysregulated oxidative balance (Liu and Zhou, 2012). Therefore, we tested whether $\alpha$-synuclein pathology or chronic corticosterone resulted in increased mitochondrial ROS production in our model, which was not the case. In summary, these results suggest that $\alpha$-synuclein pathology as defined here (immunoreactivity to pS129 and C-terminal truncated, insoluble forms of $\alpha$-synuclein) and five to six weeks postinjection is not sufficient to induce clear mitochondrial dysfunction in the mouse amygdala and striatum. The additional challenge of the amygdala circuits with corticosterone did not result in mitochondrial dysfunction, although it might have blocked mitochondrial adaptations in response to $\alpha$-synuclein pathology formation. A summary of the reported findings is given in Figure 5.

Importantly, as we did not observe pS129 $\alpha$-synuclein in the striatum or amygdala by Western blotting five to six weeks after PFF injection, even in the insoluble fractions, we assume that at this time point pS129-positive, insoluble aggregates were too rare to be detected. Conversely, by immunostaining pS129 $\alpha$-synuclein was readily detected. This could mean that pS129-positive $\alpha$-synuclein pathology precedes the formation of insoluble aggregates, which is consistent with our recent study on the successive maturation of pS129 $\alpha$-synuclein-positive aggregates into Lewy body-like structures (MahulMellier et al., 2020).

A limitation of the study performed here is the possibility that mitochondrial dysfunction was not detected because the number of affected neurons was too low for changes to be recognized. While we cannot exclude this possibility, which warrants further investigation, we demonstrated that overall brain region respirational patterns were also maintained in the presence of dense pS129 $\alpha$-synuclein pathology. On the other hand, the chronic supply of exogenous corticosterone increased mitochondrial respiration in the amygdala independent of pS129 $\alpha$-synuclein pathology.

The primary aim of this study was to investigate whether $\alpha$-synuclein pathology immediately results in mitochondrial dysfunction. We deem that for this purpose, the inclusion of only male mice was sufficient, given that the incidence of synucleinopathies is higher in men than it is in women (Savica et al., 2013). However, this divergent incidence warrants specific investigation of sex-specific differences in the interaction of $\alpha$-synuclein pathology and mitochondrial dysfunction in future studies.

\section{Conclusions}

Both $\alpha$-synuclein pathology and mitochondrial dysfunction have been implicated in the pathogenesis of PD and other synucleinopathies. Despite recent advances in the elucidation of the molecular underpinnings of both processes, it remains unclear how $\alpha$-synuclein pathology influences mitochondrial function in vivo and vice versa and 
Table 2: Summary of high-resolution respirometry data

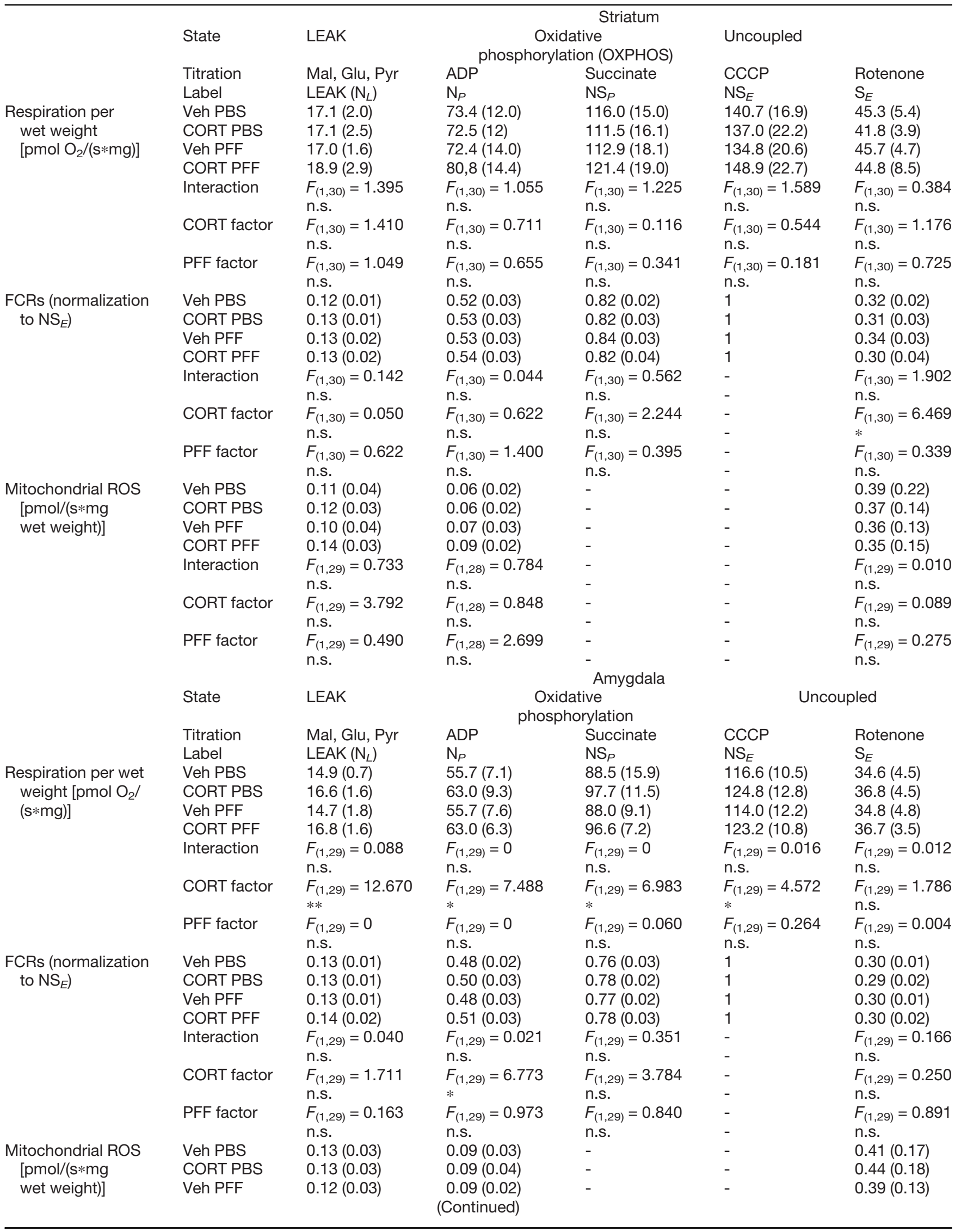




\begin{tabular}{|c|c|c|c|c|c|}
\hline State & LEAK & $\begin{array}{r}\text { O } \\
\text { phos }\end{array}$ & $\begin{array}{l}\text { tive } \\
\text { orylation }\end{array}$ & & ipled \\
\hline Titration & Mal, Glu, Pyr & ADP & Succinate & CCCP & Rotenone \\
\hline Label & $\operatorname{LEAK}\left(\mathrm{N}_{L}\right)$ & & $\mathrm{NS}_{P}$ & $\mathrm{NS}_{E}$ & \\
\hline CORT PFF & $0.15(0.03)$ & $0.09(0.02)$ & - & - & $0.40(0.19)$ \\
\hline Interaction & $\begin{array}{l}F_{(1,28)}=1.142 \\
\text { n.s. }\end{array}$ & $\begin{array}{l}F_{(1,27)}=0.095 \\
\text { n.s. }\end{array}$ & - & $\begin{array}{l}- \\
-\end{array}$ & $\begin{array}{l}F_{(1,28)}=0.026 \\
\text { n.s. }\end{array}$ \\
\hline CORT factor & $\begin{array}{l}F_{(1,28)}=1.423 \\
\text { n.s. }\end{array}$ & $\begin{array}{l}F_{(1,27)}=0.203 \\
\text { n.s. }\end{array}$ & $\begin{array}{l}- \\
-\end{array}$ & $\begin{array}{l}- \\
-\end{array}$ & $\begin{array}{l}F_{(1,28)}=0.089 \\
\text { n.s. }\end{array}$ \\
\hline $\begin{array}{l}\text { PFF factor } \\
\text { n.s. }\end{array}$ & $\begin{array}{l}F_{(1,28)}=0.009 \\
\text { n.s. }\end{array}$ & $F_{(1,27)}=0.159$ & - & n.s. & $F_{(1,28)}=0.210$ \\
\hline
\end{tabular}

Mean values (SD) are given for the different conditions with details on statistical tests (two-way ANOVAs) in the rows below them; $* p<0.05$ and $* * p<0.01$.
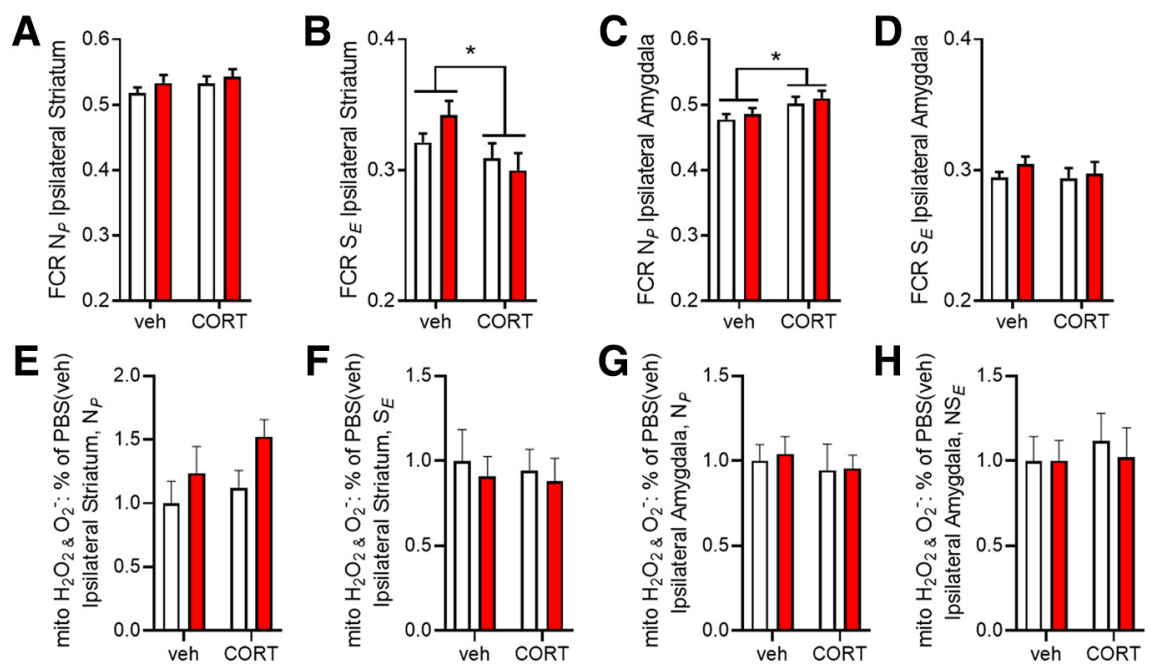

Figure 4. FCRs and mitochondrial ROS. FCRs are presented for the striatum $(\boldsymbol{A}, \boldsymbol{B})$ and amygdala $(\boldsymbol{C}, \boldsymbol{D})$. Mitochondrial ROS production was similar across groups in both in the striatum $(\boldsymbol{E}, \boldsymbol{F})$ and the amygdala $(\boldsymbol{G}, \boldsymbol{H})$. Two-way ANOVA was performed; see Table 2 for detailed results. The main effects of CORT are indicated; $* p<0.05$.

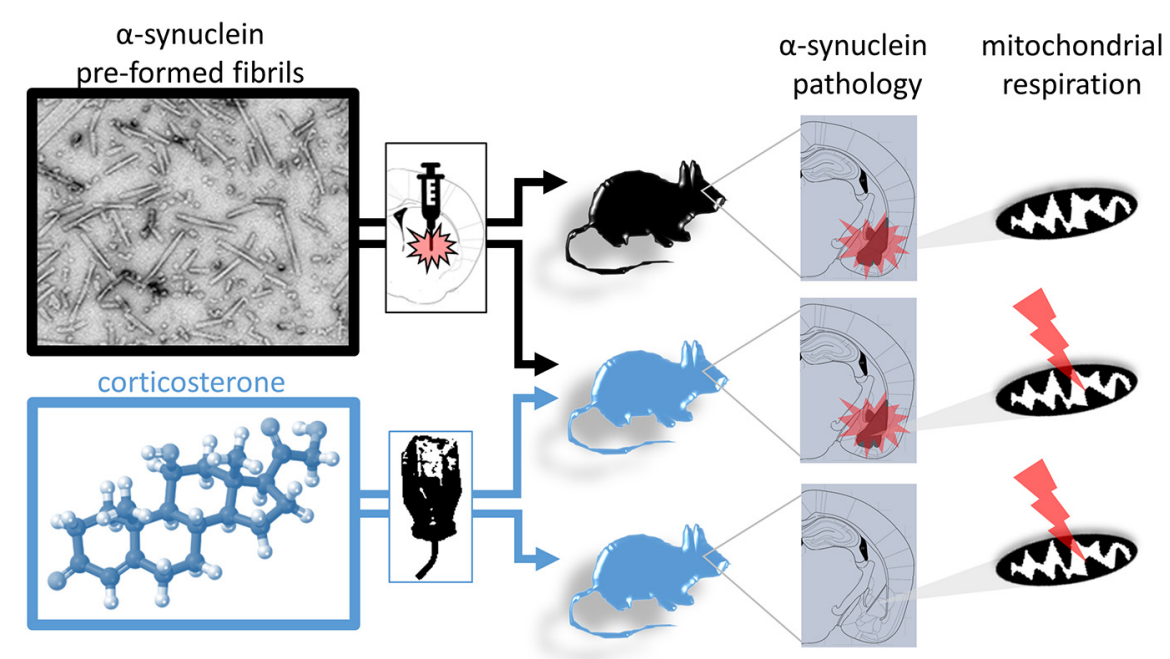

Figure 5. Working model. While chronic corticosterone induced respirational hyperactivity in the amygdala and PFF inoculation resulted in pronounced levels of pathologic $\alpha$-synuclein, no deficits of mitochondrial respiration were observed as a result of $\alpha$-synuclein pathology formation. 
whether one or both of these hallmarks are sufficient to cause neurodegeneration and the manifestation of clinical symptoms. Our results suggest that the prominent $\alpha$-synuclein pathology observed at five to six weeks postinoculation with PFFs and, as defined above, is not sufficient to induce mitochondrial dysfunction. Although significant cell loss in the substantia nigra in this model is usually only detected six months after intrastriatal PFF injection (Luk et al., 2012), we expected pronounced levels of pathologic $\alpha$-synuclein early after seeding to have effects on mitochondrial function. A recent report demonstrated a non-significant trend toward a reduction in neuron numbers in the basolateral amygdala only six months after bilateral injection of high PFF concentrations (Stoyka et al., 2020).

Our findings suggest that mitochondrial dysfunction may occur later, possibly during post $\alpha$-synuclein aggregation events linked to the transition from pS129 immunoreactive filamentous aggregates to LBs, which also involve the recruitment of mitochondria and other membranous organelles into LBs (for review, see Lashuel, 2020). Indeed, recent studies in primary neuron models have shown that recruitment of mitochondria and mitochondrial dysfunction occur primarily at later stages of LB formation and maturation (Mahul-Mellier et al., 2020). Together, these findings highlight the critical importance of revisiting the interplay between $\alpha$-synuclein and mitochondria at the various stages on the pathway to LB formation and their roles in LB formation and maturation and neurodegeneration in this model and other animal models of PD pathology and synucleinopathies.

Our findings demand caution regarding the translational validity of this PFF injection model, given the weak symptomatology, in particular of non-motor symptoms, even at the peak of $\alpha$-synuclein pathology in this model (one to three months after injection of PFFs; Burtscher et al., 2019). It is noteworthy that it appears to be challenging to reproduce motor symptoms in this PFF inoculation model, even at the late stages of pathology formation. For example, recently Henderson et al. (2019) reported no deficits in rotarod-assessed motor coordination even up to nine months after PFF injection, despite this being one of the most replicated features in this model (Luk et al., 2012; Kim et al., 2019). We also warn about potential publication bias, with negative reports on this model not being publicly shared and discussed, and we hope that our report encourages other scientists to share and discuss their negative findings.

\section{References}

Baba M, Nakajo S, Tu PH, Tomita T, Nakaya K, Lee VM, Trojanowski JQ, Iwatsubo T (1998) Aggregation of alpha-synuclein in Lewy bodies of sporadic Parkinson's disease and dementia with Lewy bodies. Am J Pathol 152:879-884.

Bacq A, Balasse L, Biala G, Guiard B, Gardier AM, Schinkel A, Louis F, Vialou V, Martres MP, Chevarin C, Hamon M, Giros B, Gautron $S$ (2012) Organic cation transporter 2 controls brain norepinephrine and serotonin clearance and antidepressant response. Mol Psychiatry 17:926-939.

Braak H, Rüb U, Gai WP, Del Tredici K (2003a) Idiopathic Parkinson's disease: possible routes by which vulnerable neuronal types may be subject to neuroinvasion by an unknown pathogen. J Neural Transm (Vienna) 110:517-536.
Braak H, Del Tredici K, Rüb U, de Vos RA, Jansen Steur EN, Braak E (2003b) Staging of brain pathology related to sporadic Parkinson's disease. Neurobiol Aging 24:197-211.

Burtscher J, Copin JC, Rodrigues J, Kumar ST, Chiki A, Guillot de Suduiraut I, Sandi C, Lashuel HA (2019) Chronic corticosterone aggravates behavioral and neuronal symptomatology in a mouse model of alpha-synuclein pathology. Neurobiol Aging 83:11-20.

Chinta SJ, Mallajosyula JK, Rane A, Andersen JK (2010) Mitochondrial $\alpha$-synuclein accumulation impairs complex I function in dopaminergic neurons and results in increased mitophagy in vivo. Neurosci Lett 486:235-239.

Desplats P, Lee HJ, Bae EJ, Patrick C, Rockenstein E, Crews L, Spencer B, Masliah E, Lee SJ (2009) Inclusion formation and neuronal cell death through neuron-to-neuron transmission of alphasynuclein. Proc Natl Acad Sci USA 106:13010-13015.

Devi L, Raghavendran V, Prabhu BM, Avadhani NG, Anandatheerthavarada HK (2008) Mitochondrial import and accumulation of alpha-synuclein impair complex I in human dopaminergic neuronal cultures and Parkinson disease brain. $J$ Biol Chem 283:9089-9100.

Di Maio R, Barrett PJ, Hoffman EK, Barrett CW, Zharikov A, Borah A, Hu X, McCoy J, Chu CT, Burton EA, Hastings TG, Greenamyre JT (2016) $\alpha$-Synuclein binds to TOM20 and inhibits mitochondrial protein import in Parkinson's disease. Sci Transl Med 8:342ra78.

Gai WP, Power JH, Blumbergs PC, Culvenor JG, Jensen PH (1999) Alpha-synuclein immunoisolation of glial inclusions from multiple system atrophy brain tissue reveals multiprotein components. $J$ Neurochem 73:2093-2100.

Gnaiger E (2009) Capacity of oxidative phosphorylation in human skeletal muscle: new perspectives of mitochondrial physiology. Int J Biochem Cell Biol 41:1837-1845.

Grassi D, Howard S, Zhou M, Diaz-Perez N, Urban NT, GuerreroGiven D, Kamasawa N, Volpicelli-Daley LA, LoGrasso P, Lasmézas Cl (2018) Identification of a highly neurotoxic $\alpha$-synuclein species inducing mitochondrial damage and mitophagy in Parkinson's disease. Proc Natl Acad Sci USA 115:E2634-E2643.

Henderson MX, Cornblath EJ, Darwich A, Zhang B, Brown H, Gathagan RJ, Sandler RM, Bassett DS, Trojanowski JQ, Lee VM (2019) Spread of $\alpha$-synuclein pathology through the brain connectome is modulated by selective vulnerability and predicted by network analysis. Nat Neurosci 22:1248-1257.

Hsu LJ, Sagara Y, Arroyo A, Rockenstein E, Sisk A, Mallory M, Wong J, Takenouchi T, Hashimoto M, Masliah E (2000) $\alpha$-Synuclein promotes mitochondrial deficit and oxidative stress. Am J Pathol 157:401-410.

Ibáñez $\mathrm{P}$, Bonnet AM, Débarges $\mathrm{B}$, Lohmann E, Tison F, Pollak $\mathrm{P}$, Agid Y, Dürr A, Brice A (2004) Causal relation between alpha-synuclein gene duplication and familial Parkinson's disease. Lancet 364:1169-1171.

Kavushansky A, Richter-Levin G (2006) Effects of stress and corticosterone on activity and plasticity in the amygdala. $\mathrm{J}$ Neurosci Res 84:1580-1587.

Kim D, Yoo JM, Hwang H, Lee J, Lee SH, Yun SP, Park MJ, Lee M, Choi S, Kwon SH, Lee S, Kwon SH, Kim S, Park YJ, Kinoshita M, Lee YH, Shin S, Paik SR, Lee SJ, Lee S, et al. (2018) Graphene quantum dots prevent $\alpha$-synucleinopathy in Parkinson's disease. Nat Nanotechnol 13:812-818.

Kim S, Kwon SH, Kam TI, Panicker N, Karuppagounder SS, Lee S, Lee JH, Kim WR, Kook M, Foss CA, Shen C, Lee H, Kulkarni S, Pasricha PJ, Lee G, Pomper MG, Dawson VL, Dawson TM, Ko HS (2019) Transneuronal propagation of pathologic $\alpha$-synuclein from the gut to the brain models Parkinson's disease. Neuron 103:627641.e7.

Kordower JH, Chu Y, Hauser RA, Freeman TB, Olanow CW (2008) Lewy body-like pathology in long-term embryonic nigral transplants in Parkinson's disease. Nat Med 14:504-506.

Krüger R, Kuhn W, Müller T, Woitalla D, Graeber M, Kösel S, Przuntek H, Epplen JT, Schöls L, Riess O (1998) Ala30Pro mutation in the gene encoding alpha-synuclein in Parkinson's disease. Nat Genet 18:106-108. 
Kumar ST, Donzelli S, Chiki A, Syed MMK, Lashuel HA (2020) A simple, versatile and robust centrifugation-based filtration protocol for the isolation and quantification of $\alpha$-synuclein monomers, oligomers and fibrils: towards improving experimental reproducibility in $\alpha$-synuclein research. J Neurochem 153:103-119.

Langston JW, Ballard P, Tetrud JW, Irwin I (1983) Chronic Parkinsonism in humans due to a product of meperidine-analog synthesis. Science 219:979-980.

Lashuel HA (2020) Do Lewy bodies contain alpha-synuclein fibrils? and does it matter? A brief history and critical analysis of recent reports. Neurobiol Dis 141:104876.

Lashuel HA, Overk CR, Oueslati A, Masliah E (2013) The many faces of $\alpha$-synuclein: from structure and toxicity to therapeutic target. Nat Rev Neurosci 14:38-48.

Li JY, Englund E, Holton JL, Soulet D, Hagell P, Lees AJ, Lashley T, Quinn NP, Rehncrona S, Björklund A, Widner H, Revesz T, Lindvall O, Brundin P (2008) Lewy bodies in grafted neurons in subjects with Parkinson's disease suggest host-to-graft disease propagation. Nat Med 14:501-503.

Liu W, Zhou C (2012) Corticosterone reduces brain mitochondrial function and expression of mitofusin, BDNF in depression-like rodents regardless of exercise preconditioning. Psychoneuroendocrinology 37:1057-1070.

Ludtmann MH, Angelova PR, Ninkina NN, Gandhi S, Buchman VL, Abramov AY (2016) Monomeric alpha-synuclein exerts a physiological role on brain ATP synthase. J Neurosci 36:10510-10521.

Ludtmann MH, Angelova PR, Horrocks MH, Choi ML, Rodrigues M, Baev AY, Berezhnov AV, Yao Z, Little D, Banushi B, Al-Menhali AS, Ranasinghe RT, Whiten DR, Yapom R, Dolt KS, Devine MJ, Gissen $\mathrm{P}$, Kunath T, Jaganjac M, Pavlov EV, et al. (2018) $\alpha$-Synuclein oligomers interact with ATP synthase and open the permeability transition pore in Parkinson's disease. Nat Commun 9:2293.

Luk KC, Kehm V, Carroll J, Zhang B, O'Brien P, Trojanowski JQ, Lee VM (2012) Pathological $\alpha$-synuclein transmission initiates Parkinson-like neurodegeneration in nontransgenic mice. Science 338:949-953.

Lukyanova LD, Kirova YI (2015) Mitochondria-controlled signaling mechanisms of brain protection in hypoxia. Front Neurosci 9:320.

Mahul-Mellier AL, Altay F, Burtscher J, Maharjan N, Bouziad NA, Chiki A, Vingill S, Wade-Martins R, Holton J, Strand C, Haikal C, Li $\mathrm{J}-\mathrm{Y}$, Hamelin R, Croisier M, Knott G, Mairet-Coello G, Weerens L, Michel A, Downey P, Citron M, Lashuel HA (2018) The making of a Lewy body: the role of alpha-synuclein post-fibrillization modifications in regulating the formation and the maturation of pathological inclusions. bioRxiv 500058. doi: https://doi.org/10.1101/500058.

Mahul-Mellier AL, Burtscher J, Maharjan N, Weerens L, Croisier M, Kuttler F, Leleu M, Knott GW, Lashuel HA (2020) The process of Lewy body formation, rather than simply $\alpha$-synuclein fibrillization, is one of the major drivers of neurodegeneration. Proc Natl Acad Sci USA 117:4971-4982.

Mao XR, Crowder CM (2010) Protein misfolding induces hypoxic preconditioning via a subset of the unfolded protein response machinery. Mol Cell Biol 30:5033-5042.

Masuda-Suzukake M, Nonaka T, Hosokawa M, Oikawa T, Arai T, Akiyama H, Mann DM, Hasegawa M (2013) Prion-like spreading of pathological $\alpha$-synuclein in brain. Brain 136:1128-1138.

Nelson PT, Abner EL, Patel E, Anderson S, Wilcock DM, Kryscio RJ, Van Eldik LJ, Jicha GA, Gal Z, Nelson RS, Nelson BG, Gal J, Azam MT, Fardo DW, Cykowski MD (2018) The Amygdala as a locus of pathologic misfolding in neurodegenerative diseases. $J$ Neuropathol Exp Neurol 77:2-20.

Polymeropoulos MH, Lavedan C, Leroy E, Ide SE, Dehejia A, Dutra A, Pike B, Root H, Rubenstein J, Boyer R, Stenroos ES, Chandrasekharappa S, Athanassiadou A, Papapetropoulos T, Johnson WG, Lazzarini AM, Duvoisin RC, Di lorio G, Golbe LI, Nussbaum RL (1997) Mutation in the alpha-synuclein gene identified in families with Parkinson's disease. Science 276:2045-2047.

Recasens A, Dehay B, Bové J, Carballo-Carbajal I, Dovero S, PérezVillalba A, Fernagut P-O, Blesa J, Parent A, Perier C, Fariñas I,
Obeso JA, Bezard E, Vila M (2014) Lewy body extracts from Parkinson disease brains trigger $\alpha$-synuclein pathology and neurodegeneration in mice and monkeys. Ann Neurol 75:351-362.

Reeve A, Ludtmann $\mathrm{MH}$, Angelova $\mathrm{P}$, Simcox $\mathrm{E}$, Horrocks $\mathrm{M}$, Klenerman D, Gandhi S, Turnbull D, Abramov A (2015) Aggregated $\alpha$-synuclein and complex I deficiency: exploration of their relationship in differentiated neurons. Cell Death Dis 6:e1820.

Rey NL, Steiner JA, Maroof N, Luk KC, Madaj Z, Trojanowski JQ, Lee VM, Brundin P (2016) Widespread transneuronal propagation of $\alpha$-synucleinopathy triggered in olfactory bulb mimics prodromal Parkinson's disease. J Exp Med 213:1759-1778.

Rey NL, Bousset L, George S, Madaj Z, Meyerdirk L, Schulz E, Steiner JA, Melki R, Brundin P (2019) $\alpha$-Synuclein conformational strains spread, seed and target neuronal cells differentially after injection into the olfactory bulb. Acta Neuropathol Commun 7:221.

Rybnikova E, Samoilov M (2015) Current insights into the molecular mechanisms of hypoxic pre- and postconditioning using hypobaric hypoxia. Front Neurosci 9:388.

Savica R, Grossardt BR, Bower JH, Boeve BF, Ahlskog JE, Rocca WA (2013) Incidence of dementia with Lewy bodies and Parkinson disease dementia. JAMA Neurol 70:1396-1402.

Schapira AH, Cooper JM, Dexter D, Jenner P, Clark JB, Marsden CD (1989) Mitochondrial complex I deficiency in Parkinson's disease. Lancet 333:1269.

Singleton AB, Farrer M, Johnson J, Singleton A, Hague S, Kachergus J, Hulihan M, Peuralinna T, Dutra A, Nussbaum R, Lincoln S, Crawley A, Hanson M, Maraganore D, Adler C, Cookson MR, Muenter M, Baptista M, Miller D, Blancato J, et al. (2003) Alpha-synuclein locus triplication causes Parkinson's disease. Science 302:841.

Sorrentino ZA, Goodwin MS, Riffe CJ, Dhillon JK, Xia Y, Gorion KM, Vijayaraghavan N, McFarland KN, Golbe LI, Yachnis AT, Giasson BI (2019) Unique $\alpha$-synuclein pathology within the amygdala in Lewy body dementia: implications for disease initiation and progression. Acta Neuropathol Commun 7:142.

Spillantini MG, Schmidt ML, Lee VM, Trojanowski JQ, Jakes R, Goedert M (1997) Alpha-synuclein in Lewy bodies. Nature 388:839-840.

Stoyka LE, Arrant AE, Thrasher DR, Russell DL, Freire J, Mahoney CL, Narayanan A, Dib AG, Standaert DG, Volpicelli-Daley LA (2020) Behavioral defects associated with amygdala and cortical dysfunction in mice with seeded $\alpha$-synuclein inclusions. Neurobiol Dis 134:104708.

Tapias V, Hu X, Luk KC, Sanders LH, Lee VM, Greenamyre JT (2017) Synthetic alpha-synuclein fibrils cause mitochondrial impairment and selective dopamine neurodegeneration in part via iNOS-mediated nitric oxide production. Cell Mol Life Sci 74:2851-2874.

Thobois S, Prange S, Sgambato-Faure V, Tremblay L, Broussolle E (2017) Imaging the etiology of apathy, anxiety, and depression in Parkinson's disease: implication for treatment. Curr Neurol Neurosci Rep 17:76.

Volpicelli-Daley LA, Luk KC, Patel TP, Tanik SA, Riddle DM, Stieber A, Meaney DF, Trojanowski JQ, Lee VM (2011) Exogenous $\alpha$-synuclein fibrils induce Lewy body pathology leading to synaptic dysfunction and neuron death. Neuron 72:57-71.

Wang X, Becker K, Levine N, Zhang M, Lieberman AP, Moore DJ, Ma $J$ (2019) Pathogenic alpha-synuclein aggregates preferentially bind to mitochondria and affect cellular respiration. Acta Neuropathol Commun 7:41.

Weilnau JN, Carcella MA, Miner KM, Bhatia TN, Hutchison DF, Pant DB, Nouraei N, Leak RK (2018) Evidence for cross-hemispheric preconditioning in experimental Parkinson's disease. Brain Struct Funct 223:1255-1273.

Zarranz JJ, Alegre J, Gómez-Esteban JC, Lezcano E, Ros R, Ampuero I, Vidal L, Hoenicka J, Rodriguez O, Atarés B, Llorens V, Gomez Tortosa E, del Ser T, Muñoz DG, de Yebenes JG (2004) The new mutation, E46K, of alpha-synuclein causes Parkinson and Lewy body dementia. Ann Neurol 55:164-173. 